\title{
Surgical anatomy of Crista fenestra of round window corridor in relation to cochlear implantation: Our experience in 140 cases
}

\author{
Saad Elzayat ${ }^{1}$, Hitham Hassan ${ }^{1}$, islam soltan ${ }^{1}$, Mona Abdel-kareem $^{1}$, and Fatthi Baki ${ }^{2}$ \\ ${ }^{1}$ Kafrelsheikh University \\ ${ }^{2}$ Alexandria University
}

June 15,2020

\begin{abstract}
Objective: This study is to describe surgical morphological types of the crista fenestra ( $\mathrm{CF}$ ) in relation to round window membrane (RWM) and to determine its impact on cochlear implant (CI) via the RW insertion. Materials and Methods: A series of 140 cases of CI which were performed in tertiary referral centers for CI with intra-operative video recording. Two senior CI surgeons reviewed these recordings for detection of morphological classification. Results: 125 cases (89.28\%) showed the type (A) CF, which sub-classified to: Type A-1 in 93 cases (66.42\%), type A-2 in 26 cases (18.57\%) and type A-3 in 6 cases (4.28\%) Type (B) CF was detected in 15 cases, which sub-classified to: Type B-1 in 11 cases (7.85\%) and type B-2 in 4 cases $(2.85 \%)$. Conclusion: In spite of large morphological diversity, Crist Fenestra can be classified into two main types. Most of them were no need for its removal whereas in a minority of the cases it hinders electrode insertion and needs drilling. KEYWORDS: Cochlear implant, round window membrane, Crista fenestra, drilling.
\end{abstract}

\section{Hosted file}

Crista Zayatblind COL 12-6-20.docx available at https://authorea.com/users/333063/articles/ 459888-surgical-anatomy-of-crista-fenestra-of-round-window-corridor-in-relation-tocochlear-implantation-our-experience-in-140-cases 